\title{
Risk of Dengue in Travelers: Implications for Dengue Vaccination
}

\author{
Annelies Wilder-Smith ${ }^{1}$
}

(C) Springer Science+Business Media, LLC, part of Springer Nature 2018

\begin{abstract}
Purpose of Review Dengue is found in tropics and subtropics that are considered to be popular travel destinations. We set out to review the burden of dengue on international travelers.

Recent Findings GeoSentinel, a global network of travel medicine providers, has seen an increasing trend of dengue in returning travelers over the past decades. In Southeast Asia, annual proportionate morbidity increased from 50 dengue cases per 1000 illreturned travelers in non-epidemic years to an average of 159 cases per 1000 travelers during epidemic years. Dengue is the leading cause of fever in returning travelers, having overtaken malaria for travelers to Southeast Asia. Most dengue seroconversion studies in travelers report an attack rate of around 5\% depending on duration of travel and destination.

Summary Dengue vaccination would be justified for travelers. The first licensed dengue vaccine CYD-TDV is only recommended in seropositive individuals. This review considers preventive measures including how best to use the first licensed dengue vaccine CYD-TDV.
\end{abstract}

Keywords Dengue $\cdot$ Travelers $\cdot$ Dengue vaccine $\cdot$ Personal protection $\cdot$ Seroconversion $\cdot$ GeoSentinel

\section{Background}

Dengue virus has become the world's most frequent Flavivirus. Transmitted by mosquitoes of the genus Aedes, dengue is found mainly in the tropics and subtropics [1, 2•] that are considered to be popular travel destinations [3]. Understanding the extent of risk of dengue in travelers is important for travelers, clinicians, and travel medicine providers. Pre-travel advice will need to consider the epidemiology of dengue, attack rates in travelers, host factors, and preventive measures. Clinicians caring for ill-returned travelers should be able to recognize dengue and be familiar with its management. Dengue infections exhibit a dynamic risk, with strong geographical heterogeneities, hence we need to improve the accuracy of risk communication combined with appropriate preventive measures $[4 \bullet \bullet]$.

This article is part of the Topical Collection on Tropical, Travel and Emerging Infections

Annelies Wilder-Smith

annelies.wilder-smith@1shtm.ac.uk

1 Department of Disease Control, London School of Hygiene and Tropical Medicine, Bloomsbury, UK
As surveillance is often just passive with mandatory dengue notifications based on illness clinically compatible with dengue often without laboratory confirmation, the true incidence is not known [5]. Modeling combined with cartographic approaches have estimated the annual incidence of dengue infections to be 400 million infections per year, with clinically apparent cases representing about $25 \%$ of all dengue virus infections [6]. However, dengue incidence is cyclical often with a 3-5-year pattern [7] and the incidence is far lower in non-epidemic years. Asia accounts for $75 \%$ of the dengue disease burden, followed by Latin America and Africa [6]. In highly endemic areas, approximately $10 \%$ of all febrile episodes are due to dengue $[8 \cdot \bullet$.

The rapid geographic spread of dengue viruses globally is the result of increasing mobility of people via modern means of transportation [9-12]. Air travel connectivity between dengue-endemic countries and from dengue-endemic countries to non-endemic, but still vulnerable settings has increased exponentially [3]. While imported dengue cases to the USA have resulted in small dengue clusters for many years [13], the first autochthonous sporadic cases in Europe (France and Croatia) were reported only in $2010[14,15]$. In 2012, the first major European outbreak of dengue occurred in Madeira [16]. Viremic travelers to non-endemic areas where Aedes 
mosquitoes exist constitute the source for triggering autochthonous transmission [17••, 18]. About $36 \%$ of travelers who acquired dengue during their travel to dengue-endemic countries returned to Europe during the acute phase of the infection (up to 7 days after symptom onset), and $58 \%$ of travelers with an acute dengue infection were viremic when seeking medical care, thus highlighting the potential for dengue virus introduction [19]. Fortunately, the seasonal window in Europe when vectorial capacity is sufficient to sustain autochthonous transmission is short [20••]. The risk of dengue importation that will lead to establishment in temperate climates such as those in Europe was modeled to be very low [17••].

The principal vector Aedes aegypti is a peri-domiciliary day-biting mosquito capable of biting several people in a short period of time. Aedes albopictus, although a less efficient vector compared to Aedes aegypti, is continuing its geographic expansion into tropical and temperate climates. Climate change with global warming facilitates a wider geographic distribution of Aedes mosquitoes, thereby increasing dengueepidemic potential in temperate regions. [21] Dengue caused an outbreak in the temperate climate of Japan in 2013 due to increasing importation via travelers from China [22]. Travelers have often served as a sentinel to unmask ongoing dengue transmission in countries before national authorities notified the outbreak $[12,23]$.

\section{Risk of Dengue in Travelers}

In parallel with the increasing incidence of dengue globally, the incidence of dengue in travelers has increased exponentially in the past decades [24, 25]. GeoSentinel is a global network of travel medicine providers that see ill-returning travelers [26]. GeoSentinel has seen an increasing trend of dengue in returning travelers over the past decades [27, 28]. In Southeast Asia, annual proportionate morbidity increased from 50 dengue cases per 1000 ill-returned travelers in nonepidemic years to an average of 159 cases per 1000 travelers during epidemic years [29]. Dengue is the leading cause of fever in returning travelers, having overtaken malaria for travelers to Southeast Asia [29]. GeoSentinel also identified the seasonality of dengue transmission [29]. Dengue occurs both in adult [29, 30] and pediatric travelers [31, 32], with one study in expats showing similar attack rates for adults (4.7\%) and children (6.3\%) [33]. However, as most travelers are adults, the majority of travel-associated dengue cases have been reported in adult travelers.

Prospective studies are better suited to determine the attack rate than sentinel surveillance. A dengue antibody seroconversion study in travelers with a median length of travel of 21 days seen in the Boston Area Travel Medicine Network found a seroconversion rate by either anti-DENV IgM or IgG ELISA between 2.9 and $6.8 \%$ [34]. Eighteen percent of those with seroconversion reported dengue-like symptoms. Seroconversion was documented for travel to Africa as well as countries and regions known to be highly dengue endemic (India, Brazil, Southeast Asia) [34]. In Swedish travelers, an increasing trend of dengue infections over time was found for most destinations [35•]. The majority of the dengue cases were acquired in Thailand (492 out of 925 travelers; 53\%), with an attack rate of 13.6 (95\% CI $12.7,14.4)$ per 100,000 travelers. However, the two highest attack rates per 100,000 travelers were found for Sri Lanka $(45.3,95 \%$ CI 34.3, 56.4) and Bangladesh $(42.6,95 \%$ CI 23.8, 61.5).

Prevalence of dengue virus infection in US travelers who have lived in or traveled to dengue-endemic countries was $19 \% ; 12 \%$ had antibodies by PRNT, $85 \%$ of whom had no history of dengue [36]. Presence of DENV antibodies was associated with years lived in dengue-endemic countries and self-reported history of dengue [36]. 5.8\% of travelers returning to Italy had IgM and/or IgG antibodies specific for dengue [37]. The seroprevalence of dengue infection in one Australian study in travelers to Asia was $4.4 \%$ and a greater number of prior trips to Asia was a predictor for dengue seropositivity [38]. Dengue was the most common laboratoryconfirmed diagnosis in travelers from Bali, reported in 5\% of travelers returning to Australia [39].

\section{Special Sub-Populations of Travelers}

Peace Corps Volunteers (and other humanitarian aid workers as well as missionaries) are often long-term travelers at particular risk for dengue. The dengue incidence rate was 1.12 cases per 1000 volunteer-months [40]. The highest rate of dengue among volunteers was reported in the Caribbean region, with a rate of 5.51 cases per 1000 volunteer-months followed by the East Asia/South Asia region (3.34) and Central America (2.55) [40]. Recent or past infection with a DENV was evident in $93 \%$ missionaries with available sera, but the sample size was very small to defer such a high prevalence for all missionaries [41]. In a serosurveillance project using predeployment and postdeployment sera collected from US Army Special Operations Forces deployed to South and Central America, Africa, and Southeast Asia showed a 13.2\% seropositivity rate [42]. Business travelers are another risk group as discussed in a recent GeoSentinel analysis [43]. Given the fact that dengue is predominantly a disease of urbanized areas [44•], even short-term travel for business in cities may pose a risk. Longer-term expats were shown to be at higher risk than the endemic population [33]. Despite increasing migration to Europe [45] and South-South migration and travel [46-48], little is known about the incidence of dengue in migrants [49, 50]. In Singapore, differences were documented for dengue severity between local and migrant Chinese [42]. In migrants now living in non-endemic countries, returning to dengue- 
endemic countries to visit friends and relatives (VFR), a higher risk of severe dengue was documented in a GeoSentinel study [51], which was most likely due to the fact that many of the VFRs already had a primary dengue infection and were hence at a higher risk of a more severe dengue. Travelers visiting friends and relatives (VFRs) often have complex pre-travel needs. Future research should focus on improving the uptake of recommended interventions in VFR travelers [52]. Given the rise of migrants especially to Europe, with importation of dengue and other infectious diseases, clinicians need to be aware of dengue, and surveillance of imported dengue via migrants would be justified especially for migrants from Southeast Asia and Latin America.

\section{Clinical Manifestations and Complications of Dengue}

In most cases, dengue is a self-limiting febrile illness with spontaneous recovery, and no interventions are needed. Clinically relevant complications develop in a proportion of these patients however, with systemic vascular leak syndrome being the predominant complication with or without hemorrhages [53]. This vasculopathy is characterized by increased vascular permeability, plasma leakage, and intravascular volume depletion, which may progress to life-threatening dengue shock syndrome $[54,55]$. The 2009 WHO dengue case classification now identifies symptomatic individuals as having "dengue" if they have no major complications, while those who experience complications in any of three categories, (a) plasma leakage severe enough to cause shock or respiratory distress, or (b) severe bleeding, or (c) severe organ impairment, are designated as having "severe dengue" [53]. There is a strong epidemiological association between development of severe complications and secondary infection [56]. Antibody dependent enhancement has been widely used to explain this phenomenon, but was only recently demonstrated in clinical epidemiological studies [57••]: progression to severe dengue appears to require certain antibody-to-virus ratios $[57 \bullet \bullet, 58 \bullet \bullet$. However, although vascular leakage is the hallmark of severe dengue, other unusual severe complications can also occur. Unusual complications include the hemophagocytic syndrome [59], myocarditis [60], other cardiac problems [60-62], and fulminant hepatitis [63]. Complications in the eye may also occur [64]. Neuroophthalmological complications usually involve the posterior segment and include visual disturbance secondary to retinal vasculopathy and optic neuropathy [65]. Dengue can manifest with a wide range of neurological features, which have been noted in $0.5-21 \%$ of patients with dengue admitted to hospital [65]. Although the association of Zika with Guillain-Barre syndrome in travelers is much stronger [66•], several cases of Guillain-Barre syndrome have also been reported to be associated with dengue [67-73]. Cases of rhabdomyolysis [74], abducens nerve palsy [75], optic neuritis [76], and strokes, especially hemorrhagic stroke symptoms have been reported because of the coagulopathy associated with dengue fever [77]. Acute encephalopathy is the most common neurological disorder associated with dengue [78]. Encephalitis is secondary to the direct central nervous system invasion of the virus and has also been reported for dengue [78].

\section{Host Factors Relevant for Travelers}

Many travelers are older adults, and older travelers may have more comorbidities [79, 80]. Diabetes has been identified as a risk factor for dengue, and so have other comorbidities such as hypertension, cardiovascular disease, and asthma [81, 82]. Travelers with sickle cell disease are thought to be at increased risk of severe dengue [83]. Pregnant women are another group at high risk for severe disease, especially during the third trimester $[84,85]$, and perinatal transmission to infants is recognized [86].

\section{Dengue Diagnosis in Travelers}

The choice of laboratory test depends on the time since onset of fever. Before day 5 of illness, during the febrile period, dengue infections may be diagnosed by virus isolation, by nucleic acid amplification tests such as reverse transcriptasepolymerase chain reaction (RT-PCR), or by detection of viral antigens such as the dengue non-structural protein 1 (NS1) by enzyme-linked immunosorbent assay (ELISA) or rapid diagnostic tests (RDTs). After days 4-5, dengue viruses and antigens disappear from the blood coincident with the appearance of dengue-specific antibodies, hence serological assays should be used [87••]. RT-PCR on specimens other than blood (urine and saliva) [88] can prolong the diagnostic window and is particularly relevant for confirming the diagnosis in returning travelers.

While rapid diagnostic tests are available for NS1 antigen or IgM antibody detection or both simultaneously, the sensitivities and specificities of the available tests are lower than the equivalent laboratory-based ELISA assays [89]. Nevertheless, the combination of NS1 antigen and IgM testing at point of care offers a longer diagnostic window, and RDTs are hence increasingly being used. NS1 antigen testing has been shown to be highly specific in travelers [90]. Diagnostic requests for both Zika virus (ZIKV) and dengue virus (DENV) infections in returning travelers have significantly increased during the recent ZIKV outbreak in the Americás [91]. As these flaviviruses have overlapping clinical syndromes and geographical distribution, diagnostic differentiation is important because of different clinical consequences. As flaviviruses are 
known to have a short-viremic period, diagnostics often rely on serological methods, which are challenging due to extensive cross-reactive antibodies. Although the DENV NS1 antigen assay was highly specific for laboratory confirmed ZIKVinfected travelers, high percentages of cross-reactivity of DENV IgM and IgG ELISÁs were found, of which diagnostic laboratories should be aware [91]. An algorithm for ZIKV serodiagnosis based on three simple ELISAs has been proposed to distinguish dengue from Zika [92].

The most urgent need is to identify biomarkers that can help discriminate patients who will progress to a more severe dengue. However, no single biomarker or combination of biomarkers have been identified to date, despite substantial efforts to this end [93].

\section{Clinical Management}

The mainstay of clinical management is prompt and appropriate rehydration therapy, avoiding both too little as well as too much fluid. A state-of-the-art review was recently published in the Lancet Clinical Seminar series [94]. The case fatality rates under good case management should be below $1 \%$ for symptomatic dengue. Travel medicine providers caring for dengue patients need to be familiar with the clinical management through specialized training [95], and training in travel and tropical medicine needs to be increasingly incorporated into undergraduate curricula [96].

\section{Preventive Measures and Vaccination}

Personal protective measures for travelers include measures taken mainly during the day to avoid mosquito bites such as repellents, long-sleeves and light clothing, and coils or other vapors [24]. Picaridin-containing repellents appears to be as effective as DEET (at 30\%), but at $>50 \%$ DEET seems to be more effective [97]. However, compliance with such measures have been found to be low in travelers [98]. Bed nets are of limited use as Aedes mosquitoes mainly bite during the day. Impregnated clothing has been suggested to be effective [99, 100], but this was not proven in a community-based trial [101]. Wolbachia as a novel vector control strategy was found to reduce outbreaks as a result of dengue importation in Northern Australia [102].

Given the overall lack of effective preventive measures, combined with the relatively high incidence of dengue in travelers, dengue vaccination would be indicated [103]. In 2015, the first dengue vaccine was licensed. CYD-TDV is a live attenuated tetravalent vaccine with yellow fever 17D virus as backbone. In the age group of 9 years and above, efficacy against hospitalized dengue and severe dengue was high, 83 and $91 \%$ respectively [104]. Subsequently, in the year 2017 , new long-term safety data were released which showed that the vaccine had a different performance depending on serostatus [105]. The analyses stratified by serostatus showed an increased risk of severe dengue in those seronegative at baseline, a risk that emerged about 30 months after the first dose regardless of age. The most plausible hypothesis is that the live attenuated CYD-TDV initiates a first immune response to dengue in seronegative persons that predisposes them to a higher risk of severe disease when they experience their next natural dengue infection [106]. The revised WHO recommendations in 2018 state that CYD-TDV vaccination is only recommended in seropositive individuals where the vaccine is efficacious and safe [87••]. Serostatus, reflecting whether or not the individual has experienced a dengue infection in the past, is determined by a serological assay. As travelers with previous travel to dengue-endemic countries will be more likely seropositive; screening will therefore need to be prioritized for travelers according to the extent of previous exposure to dengue $[107 \bullet \bullet]$. The specificity of a serological assay will depend on the extent of exposure to other flaviviruses such as Zika, West Nile, tick-borne Encephalitis (TBE), Japanese encephalitis, (JE) yellow fever (YF) viruses, and others, or vaccination with Flavivirus vaccines [108]. The efficacy trials were done with a three-dose schedule, 6 months apart, which will make completion of the primary schedule prior to travel unfeasible. However, the vaccine efficacy between the first and second dose and second and third doses was similar to the vaccine efficacy after the third dose, in the overall trial population in the multi-center phase 3 trials [109]. Although no long-term efficacy data for one or two dose schedules exist because the completion rate of three doses was very high in the trials, it could be argued that a single dose prior to travel may suffice in those traveling for less than 6 months [107••].

Besides CYD-TDV, two other chimeric live attenuated dengue vaccines are now in the phase 3 trials. Whether these second-generation dengue vaccines will encounter the same safety issue in seronegative vaccines is unknown. The first read-outs of the trials will most likely be available by mid2019.

\section{Concluding Remarks}

Dengue infection in international travelers is not infrequent and may be associated with substantial morbidity and undesired interruption of travel. Given widespread risk of dengue, travel medicine counseling should include information on the risk of dengue in endemic areas and advice on preventing insect bites and seeking prompt medical attention for febrile illness. The first licensed dengue vaccine CYD-TDV could be considered in laboratory-confirmed seropositive travelers; however, it is not yet licensed in most countries. Good risk 
maps are needed to provide evidence-informed advice on at risk destinations, such as those published by the Centers for Disease Control, USA [4••]. Graded evidence for best practices [110] will be needed for both pre-travel advice and clinical management of travelers with dengue.

\section{Compliance with Ethical Standards}

Conflict of Interest The author declares that she has no conflict of interest.

Human and Animal Rights and Informed Consent This article does not contain any studies with human or animal subjects performed by any of the authors.

Disclaimer AWS is consultant to the World Health Organization. The author alone is responsible for the views expressed in this publication, and her views do not necessarily represent the decisions or policies of the World Health Organization.

\section{References}

Papers of particular interest, published recently, have been highlighted as:

- Of importance

•- Of major importance

1. Kraemer MU, Sinka ME, Duda KA, Mylne AQ, Shearer FM, Barker CM, et al. The global distribution of the arbovirus vectors Aedes aegypti and Ae. albopictus. Elife. 2015;4:e08347.

2. Wilder-Smith A, Gubler DJ, Weaver SC, Monath TP, Heymann DL, Scott TW. Epidemic arboviral diseases: priorities for research and public health. Lancet Infect Dis. 2017;17(3):e101-e6 elaborates on reasons for the emergence of Aedes-transmitted diseases.

3. Glaesser D, Kester J, Paulose H, Alizadeh A, Valentin B. Global travel patterns: an overview. J Travel Med. 2017;24(4)

4.• Jentes ES, Lash RR, Johansson MA, Sharp TM, Henry R, Brady OJ, et al. Evidence-based risk assessment and communication: a new global dengue-risk map for travellers and clinicians. J Travel Med. 2016;23(6). Provides a new approach to dengue risk mapping.

5. Tissera H, Amarasinghe A, Gunasena S, DeSilva AD, Yee LW, Sessions O, et al. Laboratory-enhanced dengue sentinel surveillance in Colombo District, Sri Lanka: 2012-2014. PLoS Negl Trop Dis. 2016;10(2):e0004477.

6. Bhatt S, Gething PW, Brady OJ, Messina JP, Farlow AW, Moyes $\mathrm{CL}$, et al. The global distribution and burden of dengue. Nature. 2013;496(7446):504-7.

7. Earnest A, Tan SB, Wilder-Smith A. Meteorological factors and El Nino southern oscillation are independently associated with dengue infections. Epidemiol Infect. 2012;140(7):1244-51.

8.• L'Azou M, Moureau A, Sarti E, Nealon J, Zambrano B, Wartel TA, et al. Symptomatic dengue in children in 10 Asian and Latin American countries. N Engl J Med. 2016;374(12):1155-66 Provides detailed information on incidence of dengue in children.

9. Huang Z, Das A, Qiu Y, Tatem AJ. Web-based GIS: the vectorborne disease airline importation risk (VBD-AIR) tool. Int $\mathrm{J}$ Health Geogr. 2012;11:33.
10. Lopez LF, Amaku M, Coutinho FA, Quam M, Burattini MN, Struchiner CJ, et al. Modeling importations and exportations of infectious diseases via travelers. Bull Math Biol. 2016;78(2):185209.

11. Quam MB, Khan K, Sears J, Hu W, Rocklov J, Wilder-Smith A. Estimating air travel-associated importations of dengue virus into Italy. J Travel Med. 2015;22(3):186-93.

12. Sessions OM, Khan K, Hou Y, Meltzer E, Quam M, Schwartz E, et al. Exploring the origin and potential for spread of the 2013 dengue outbreak in Luanda, Angola. Glob Health Action. 2013;6:21822.

13. Adalja AA, Sell TK, Bouri N, Franco C. Lessons learned during dengue outbreaks in the United States, 2001-2011. Emerg Infect Dis. 2012;18(4):608-14.

14. La Ruche G, Souares Y, Armengaud A, Peloux-Petiot F, Delaunay $\mathrm{P}$, Despres $\mathrm{P}$, et al. First two autochthonous dengue virus infections in metropolitan France, September 2010. Euro Surveill. 2010;15(39):19676.

15. Gjenero-Margan I, Aleraj B, Krajcar D, Lesnikar V, Klobucar A, Pem-Novosel I, et al. Autochthonous dengue fever in Croatia, August-September 2010. Euro Surveill. 2011;16(9).

16. Wilder-Smith A, Quam M, Sessions O, Rocklov J, LiuHelmersson J, Franco L, et al. The 2012 dengue outbreak in Madeira: exploring the origins. Euro Surveill. 2014;19(8):20718.

17.• Massad E, Amaku M, Coutinho FAB, Struchiner CJ, Burattini $\mathrm{MN}$, Khan $\mathrm{K}$, et al. Estimating the probability of dengue virus introduction and secondary autochthonous cases in Europe. Sci Rep. 2018;8(1):4629 Novel modeling approaches were used to estimate the threat of dengue to Europe.

18. Cnops L, Franco L, Van Meensel B, Van den Ende J, Paz SanchezSeco M, Van Esbroeck M. Three cases of imported dengue virus infection from Madeira to Belgium, 2012. J Travel Med. 2014;21(5):344-8.

19. Neumayr A, Munoz J, Schunk M, Bottieau E, Cramer J, Calleri G, et al. Sentinel surveillance of imported dengue via travellers to Europe 2012 to 2014: TropNet data from the DengueTools Research Initiative. Euro Surveill. 2017;22(1).

20.• Liu-Helmersson J, Quam M, Wilder-Smith A, Stenlund H, Ebi K, Massad E, et al. Climate change and Aedes vectors: 21 st century projections for dengue transmission in Europe. EBioMedicine. 2016;7:267-77 Highlights the risk of further spread of Aedes to Europe.

21. Rocklov J, Quam MB, Sudre B, German M, Kraemer MU, Brady $\mathrm{O}$, et al. Assessing seasonal risks for the introduction and mosquito-borne spread of Zika virus in Europe. EBioMedicine. 2016;9:250-6.

22. Quam MB, Sessions O, Kamaraj US, Rocklov J, Wilder-Smith A. Dissecting Japan's dengue outbreak in 2014. Am J Trop Med Hyg. 2016;94(2):409-12.

23. Schwartz E, Meltzer E, Mendelson M, Tooke A, Steiner F, Gautret $\mathrm{P}$, et al. Detection on four continents of dengue fever cases related to an ongoing outbreak in Luanda, Angola, March to May 2013. Euro Surveill. 2013;18(21).

24. Wilder-Smith A, Schwartz E. Dengue in travelers. N Engl J Med. 2005;353(9):924-32.

25. Wilder-Smith A, Gubler DJ. Geographic expansion of dengue: the impact of international travel. Med Clin North Am. 2008;92(6): 1377-90 x.

26. Freedman DO, Kozarsky PE, Weld LH, Cetron MS. GeoSentinel: the global emerging infections sentinel network of the International Society of Travel Medicine. J Travel Med. 1999;6(2):94-8

27. McCarthy AE, Weld LH, Barnett ED, So H, Coyle C, Greenaway $\mathrm{C}$, et al. Spectrum of illness in international migrants seen at GeoSentinel clinics in 1997-2009, part 2: migrants resettled 
internationally and evaluated for specific health concerns. Clin Infect Dis. 2013;56(7):925-33.

28. Leder K, Torresi J, Brownstein JS, Wilson ME, Keystone JS, Barnett E, et al. Travel-associated illness trends and clusters, 2000-2010. Emerg Infect Dis. 2013;19(7):1049-73.

29. Schwartz E, Weld LH, Wilder-Smith A, von Sonnenburg F, Keystone JS, Kain KC, et al. Seasonality, annual trends, and characteristics of dengue among ill returned travelers, 1997-2006. Emerg Infect Dis. 2008;14(7):1081-8.

30. Masyeni S, Yohan B, Somia IKA, Myint KSA, Sasmono RT. Dengue infection in international travellers visiting Bali, Indonesia. J Travel Med. 2018;25(1).

31. Poddighe D, Bonomelli I, Giardinetti S, Nedbal M, Bruni P. Paediatric dengue fever diagnosed through parents' epidemiologic report and preventive strategy during the acute phase of infection. J Travel Med. 2016;23(1).

32. Rabinowicz S, Schwartz E. Morbidity among Israeli paediatric travellers. J Travel Med. 2017;24(6).

33. Neuberger A, Turgeman A, Lustig Y, Schwartz E. Dengue fever among Israeli expatriates in Delhi, 2015: implications for dengue incidence in Delhi, India. J Travel Med. 2016;23(3).

34. Olivero RM, Hamer DH, MacLeod WB, Benoit CM, SanchezVegas C, Jentes ES, et al. Dengue virus seroconversion in travelers to dengue-endemic areas. Am J Trop Med Hyg. 2016.

35. Rocklov J, Lohr W, Hjertqvist M, Wilder-Smith A. Attack rates of dengue fever in Swedish travellers. Scand J Infect Dis. 2014;46(6):412-7 Calculates attack rates, as both the numerator and denominator are known.

36. Sanchez-Vegas C, Hamer DH, Chen LH, Wilson ME, Benoit C, Hunsperger E, et al. Prevalence of dengue virus infection in US travelers who have lived in or traveled to dengue-endemic countries. J Travel Med. 2013;20(6):352-60.

37. Loconsole D, Metallo A, De Robertis AL, Morea A, Quarto M, Chironna M. Seroprevalence of dengue virus, West Nile virus, chikungunya virus, and Zika virus in international travelers attending a travel and migration center in 2015-2017, Southern Italy. Vector Borne Zoonotic Dis. 2018;18(6):331-4.

38. Ratnam I, Black J, Leder K, Biggs BA, Matchett E, Padiglione A, et al. Incidence and seroprevalence of dengue virus infections in Australian travellers to Asia. Eur J Clin Microbiol Infect Dis. 2012;31(6):1203-10

39. Sohail A, McGuinness SL, Lightowler R, Leder K, Jomon B, Bain $\mathrm{CA}$, et al. Spectrum of illness among returned Australian travellers from Bali, Indonesia: a 5-year retrospective observational study. Intern Med J. 2018.

40. Ferguson RW, Henderson SJ, Lee EA, Jung P. Dengue in peace corps volunteers, 2000-14. J Travel Med. 2016;23(3).

41. Moncayo AC, Baumblatt J, Thomas D, Harvey KA, Atrubin D, Stanek D, et al. Dengue among American missionaries returning from Jamaica, 2012. Am J Trop Med Hyg. 2015;92(1):69-71.

42. Caci JB, Blaylock JM, De La Barrera R, Griggs AN, Lin L, Jarman RG, et al. Seroprevalence of dengue fever in US Army special operations forces: initial results and the way ahead. J Spec Oper Med. 2014;14(3):111-5.

43. Chen LH, Leder K, Barbre KA, Schlagenhauf P, Libman M, Keystone J, et al. Business travel-associated illness: a GeoSentinel analysis. J Travel Med. 2018;25(1).

44. - Struchiner CJ, Rocklov J, Wilder-Smith A, Massad E. Increasing dengue incidence in Singapore over the past 40 years: population growth, climate and mobility. PLoS One. 2015;10(8):e0136286 Best evidence that population density is the main driver for dengue resurgence.

45. Pavli A, Maltezou H. Health problems of newly arrived migrants and refugees in Europe. J Travel Med. 2017;24(4).
46. Olanwijitwong J, Piyaphanee W, Poovorawan K, Lawpoolsri S, Chanthavanich P, Wichainprasast $\mathrm{P}$, et al. Health problems among Thai tourists returning from India. J Travel Med. 2017;24(4).

47. Sadarangani SP, Lim PL, Vasoo S. Infectious diseases and migrant worker health in Singapore: a receiving country's perspective. J Travel Med. 2017;24(4)

48. Simkhada PP, Regmi PR, van Teijlingen E, Aryal N. Identifying the gaps in Nepalese migrant workers' health and well-being: a review of the literature. J Travel Med. 2017;24(4).

49. Xu C, Pang J, Hsu JP, Leo YS, Lye DCB. Differences in clinical features and dengue severity between local and migrant Chinese with dengue infection in Singapore. PLoS One. 2018;13(8): e0201441.

50. Seet RC, Ooi EE, Wong HB, Paton NI. An outbreak of primary dengue infection among migrant Chinese workers in Singapore characterized by prominent gastrointestinal symptoms and a high proportion of symptomatic cases. J Clin Virol. 2005;33(4):33640.

51. Leder K, Tong S, Weld L, Kain KC, Wilder-Smith A, von Sonnenburg F, et al. Illness in travelers visiting friends and relatives: a review of the GeoSentinel Surveillance Network. Clin Infect Dis. 2006;43(9):1185-93.

52. Rowe K, Chaves N, Leder K. Challenges to providing pre-travel care for travellers visiting friends and relatives: an audit of a specialist travel medicine clinic. J Travel Med. 2017;24(5).

53. WHO. Dengue: guidelines for diagnosis, treatment, prevention and control - New edition. Switzerland: World Health Organization; 2009. $147 \mathrm{p}$

54. Lam PK, Tam DT, Diet TV, Tam CT, Tien NT, Kieu NT, et al Clinical characteristics of dengue shock syndrome in Vietnamese children: a 10-year prospective study in a single hospital. Clin Infect Dis. 2013;57(11):1577-86.

55. Rosenberger KD, Lum L, Alexander N, Junghanss T, Wills B, Jaenisch $\mathrm{T}$, et al. Vascular leakage in dengue-clinical spectrum and influence of parenteral fluid therapy. Tropical Med Int Health. 2016;21(3):445-53.

56. Halstead SB, Udomsakdi S, Simasthien P, Singharaj P, Sukhavachana P, Nisalak A. Observations related to pathogenesis of dengue hemorrhagic fever. I. Experience with classification of dengue viruses. Yale J Biol Med. 1970;42(5):261-75.

57.• Salje H, Cummings DAT, Rodriguez-Barraquer I, Katzelnick LC, Lessler J, Klungthong C, et al. Reconstruction of antibody dynamics and infection histories to evaluate dengue risk. Nature. 2018;557(7707):719-23 Best evidence on the impact of certain antibody ratios that determine the risk of severe dengue.

58.• Katzelnick LC, Gresh L, Halloran ME, Mercado JC, Kuan G, Gordon A, et al. Antibody-dependent enhancement of severe dengue disease in humans. Science. 2017;358(6365):929-32 Best evidence on the impact of certain antibody ratios that determine the risk of severe dengue.

59. Kobayashi K, Hikone M, Sakamoto N, Iwabuchi S, Kashiura M, Takasaki T, et al. Dengue-associated hemophagocytic syndrome in a Japanese traveler: a case report. J Travel Med. 2015;22(1):64 6.

60. Zea D, Foley K, Carey J. Myocarditis in a traveler returning from the Dominican Republic: an unusual presentation of dengue fever. Am J Trop Med Hyg. 2014;91(1):156-8.

61. Kirawittaya T, Yoon IK, Wichit S, Green S, Ennis FA, Gibbons $\mathrm{RV}$, et al. Evaluation of cardiac involvement in children with dengue by serial echocardiographic studies. PLoS Negl Trop Dis. 2015;9(7):e0003943.

62. Yacoub S, Wertheim H, Simmons CP, Screaton G, Wills B. Cardiovascular manifestations of the emerging dengue pandemic. Nat Rev Cardiol. 2014;11(6):335-45.

63. Ling LM, Wilder-Smith A, Leo YS. Fulminant hepatitis in dengue haemorrhagic fever. J Clin Virol. 2007;38(3):265-8. 
64. Ng AW, Teoh SC. Dengue eye disease. Surv Ophthalmol. 2015;60(2):106-14.

65. Carod-Artal FJ, Wichmann O, Farrar J, Gascon J. Neurological complications of dengue virus infection. Lancet Neurol. 2013;12(9):906-19.

66. Wilder-Smith A, Chang CR, Leong WY. Zika in travellers 19472017: a systematic review. J Travel Med. 2018;25(1). Review on Zika in travelers.

67. Dalugama C, Shelton J, Ekanayake M, Gawarammana IB. Dengue fever complicated with Guillain-Barre syndrome: a case report and review of the literature. J Med Case Rep. 2018;12(1): 137.

68. Tang X, Zhao S, Chiu APY, Wang X, Yang L, He D. Analysing increasing trends of Guillain-Barre syndrome (GBS) and dengue cases in Hong Kong using meteorological data. PLoS One. 2017;12(12):e0187830.

69. Boo YL, Aris MAM, Chin PW, Sulaiman WAW, Basri H, Hoo FK. Guillain-Barre syndrome complicating dengue fever: two case reports. Ci Ji Yi Xue Za Zhi. 2016;28(4):157-9.

70. Vieira M, Cruz ACR, Barros ANM, Costa DL, Silva E, Batista FMA, et al. Guillain-Barre syndrome and dengue-like disease in 2015: temporal relationship in Piaui state and implications on Zika virus surveillance. Rev Inst Med Trop Sao Paulo. 2017;59:e22.

71. Fragoso YD, Gomes S, Brooks JB, Matta AP, Ruocco HH, Tauil $\mathrm{CB}$, et al. Guillain-Barre syndrome and dengue fever: report on ten new cases in Brazil. Arq Neuropsiquiatr. 2016;74(12):1039-40.

72. Simon O, Billot S, Guyon D, Daures M, Descloux E, Gourinat $\mathrm{AC}$, et al. Early Guillain-Barre syndrome associated with acute dengue fever. J Clin Virol. 2016;77:29-31.

73. Ralapanawa DM, Kularatne SA, Jayalath WA. Guillain-Barre syndrome following dengue fever and literature review. BMC Res Notes. 2015;8:729.

74. Lim M, Goh HK. Rhabdomyolysis following dengue virus infection. Singap Med J. 2005;46(11):645-6.

75. Shivanthan MC, Ratnayake EC, Wijesiriwardena BC, Somaratna KC, Gamagedara LK. Paralytic squint due to abducens nerve palsy: a rare consequence of dengue fever. BMC Infect Dis. 2012;12: 156.

76. Ramos JM, Tello A, Alzamora A, Ramon ML. Optic neuritis in a traveler returning from Dominican Republic to Spain with dengue virus infection. J Travel Med. 2015;22(2):133-5.

77. Kumar J, Kumar A, Gupta S, Jain D. Dengue haemorrhagic fever: an unusual cause of intracranial haemorrhage. BMJ Case Rep. 2009;2009:bcr2006100909.

78. Verma R, Sahu R, Holla V. Neurological manifestations of dengue infection: a review. J Neurol Sci. 2014;346(1-2):26-34.

79. Gautret P, Gaudart J, Leder K, Schwartz E, Castelli F, Lim PL, et al. Travel-associated illness in older adults $(>60 \mathrm{y})$. J Travel Med. 2012;19(3):169-77.

80. Flaherty GT, Rossanese A, Steffen R, Torresi J. A golden age of travel: advancing the interests of older travellers. J Travel Med. 2018.

81. Pang J, Hsu JP, Yeo TW, Leo YS, Lye DC. Diabetes, cardiac disorders and asthma as risk factors for severe organ involvement among adult dengue patients: a matched case-control study. Sci Rep. 2017;7:39872.

82. Pang J, Salim A, Lee VJ, Hibberd ML, Chia KS, Leo YS, et al. Diabetes with hypertension as risk factors for adult dengue hemorrhagic fever in a predominantly dengue serotype 2 epidemic: a case control study. PLoS Negl Trop Dis. 2012;6(5):e1641.

83. Willen SM, Thornburg CD, Lantos PM. Travelers with sickle cell disease. J Travel Med. 2014;21(5):332-9.

84. Bich TD, Pham OK, Hai DH, Nguyen NM, Van HN, The TD, et al. A pregnant woman with acute cardiorespiratory failure: dengue myocarditis. Lancet. 2015;385(9974):1260.
85. Hariyanto H, Yahya CQ, Wibowo P, Tampubolon OE. Management of severe dengue hemorrhagic fever and bleeding complications in a primigravida patient: a case report. J Med Case Rep. 2016;10(1):357.

86. Basurko C, Matheus S, Hilderal H, Everhard S, Restrepo M, Cuadro-Alvarez E, et al. Estimating the risk of vertical transmission of dengue: a prospective study. Am J Trop Med Hyg. 2018;98:1826-32.

87.• Dengue vaccine: WHO position paper-September 2018. Wkly Epidemiol Rec. 2018;93 457-76. Summarizes the characteristics and safety issues of CYD-TDV.

88. Andries AC, Duong V, Ly S, Cappelle J, Kim KS, Lorn Try P, et al. Value of routine dengue diagnostic tests in urine and saliva specimens. PLoS Negl Trop Dis. 2015;9(9):e0004100.

89. Hunsperger EA, Yoksan S, Buchy P, Nguyen VC, Sekaran SD, Enria DA, et al. Evaluation of commercially available diagnostic tests for the detection of dengue virus NS1 antigen and antidengue virus IgM antibody. PLoS Negl Trop Dis. 2014;8(10): e3171.

90. Fuchs I, Bin H, Schlezinger S, Schwartz E. NS1 antigen testing for the diagnosis of dengue in returned Israeli travelers. J Med Virol. 2014;86(12):2005-10.

91. van Meer MPA, Mogling R, Klaasse J, Chandler FD, Pas SD, van der Eijk AA, et al. Re-evaluation of routine dengue virus serology in travelers in the era of Zika virus emergence. J Clin Virol. 2017;92:25-31.

92. Tsai WY, Youn HH, Brites C, Tsai JJ, Tyson J, Pedroso C, et al. Distinguishing secondary dengue virus infection from Zika virus infection with previous dengue by a combination of 3 simple serological tests. Clin Infect Dis. 2017;65(11):1829-36.

93. Lee YH, Leong WY, Wilder-Smith A. Markers of dengue severity: a systematic review of cytokines and chemokines. J Gen Virol. 2016;97(12):3103-19.

94. Wilder-Smith A, Ooi EE, Horstick O, Wills B. Dengue. The Lancet 2018; in print.

95. Piyaphanee W, Chanthavanich P. Residency training in travel medicine-a 3-year journey to become a specialist. J Travel Med. 2016;23(5).

96. Flaherty G, Thong Zi Yi C, Browne R. The missing link: introducing travel medicine into the undergraduate medical curriculum. J Travel Med. 2016;23(5).

97. Goodyer L, Schofield S. Mosquito repellents for the traveller: does picaridin provide longer protection than DEET? J Travel Med. 2018;25(suppl 1):S10-S5.

98. Lalani T, Yun H, Tribble D, Ganesan A, Kunz A, Fairchok M, et al. A comparison of compliance rates with anti-vectorial protective measures during travel to regions with dengue or chikungunya activity, and regions endemic for Plasmodium falciparum malaria. J Travel Med. 2016;23(5).

99. Orsborne J, DeRaedt Banks S, Hendy A, Gezan SA, Kaur H, Wilder-Smith A, et al. Personal protection of permethrin-treated clothing against Aedes aegypti, the vector of dengue and Zika virus, in the laboratory. PLoS One. 2016;11(5):e0152805.

100. DeRaedt Banks S, Orsborne J, Gezan SA, Kaur H, Wilder-Smith A, Lindsey SW, et al. Permethrin-treated clothing as protection against the dengue vector, Aedes aegypti: extent and duration of protection. PLoS Negl Trop Dis. 2015;9(10):e0004109.

101. Kittayapong P, Olanratmanee P, Maskhao P, Byass P, Logan J, Tozan Y, et al. Mitigating diseases transmitted by Aedes mosquitoes: a cluster-randomised trial of permethrin-impregnated school uniforms. PLoS Negl Trop Dis. 2017;11(1):e0005197.

102. Ritchie SA. Wolbachia and the near cessation of dengue outbreaks in northern Australia despite continued dengue importations via travellers. J Travel Med. 2018.

103. Wilder-Smith A. Dengue vaccines for travelers: has the time come? J Travel Med. 2015;22(3):200-2. 
104. Hadinegoro SR, Arredondo-Garcia JL, Capeding MR, Deseda C, Chotpitayasunondh T, Dietze R, et al. Efficacy and long-term safety of a dengue vaccine in regions of endemic disease. $\mathrm{N}$ Engl J Med. 2015;373(13):1195-206.

105. Sridhar S, Luedtke A, Langevin E, Zhu M, Bonaparte M, Machabert T, et al. Effect of dengue serostatus on dengue vaccine safety and efficacy. N Engl J Med. 2018;379:327-40.

106. Wilder-Smith A. Four-year safety follow-up of the tetravalent dengue vaccine CYD-TDV. Clin Microbiol Infect. 2018;24: $680-1$.

107.• Wilder-Smith A. Serostatus-dependent performance of the first licensed dengue vaccine: implications for travellers. J Travel
Med. 2018;25(1). Critically analyses the serostatus-dependent performance of CYD-TDV dengue vaccine, and the implications for travelers.

108. Arien KK, Wilder-Smith A. Dengue vaccine: reliably determining previous exposure. Lancet Glob Health. 2018;6:e830-1.

109. Hadinegoro SR, Arredondo-Garcia JL, Capeding MR, Deseda C, Chotpitayasunondh T, Dietze R, et al. Efficacy and long-term safety of a dengue vaccine in regions of endemic disease. $\mathrm{N}$ Engl J Med. 2015.

110. Torresi J, Steffen R. Redefining priorities towards graded travelrelated infectious disease research. J Travel Med. 2017;24(6). 